\title{
Effects of rocuronium and vecuronium on initial rundown of endplate potentials in the isolated phrenic nerve diaphragm preparation of rats
}

\author{
Jun $\mathrm{Li}^{1^{*}}$, Yong-Qin Liu ${ }^{1}$ and Han-Ting Zhang ${ }^{2^{*}}$
}

\begin{abstract}
Rocuronium and vecuronium, two non-depolarizing neuromuscular blockers, have been widely used in surgery procedures. However, their electrophysiological properties need to be more widely explored. We examined the effects of rocuronium and vecuronium on initial rundown of endplate potential amplitudes in the non-uniform stretched muscle preparation of the rat isolated phrenic nerve diaphragm. More specifically, the endplate potentials were recorded with one microelectrode from a single endplate. The effects of rocuronium or vecuronium each at 4 concentrations $(0.5 \times, 1 \times, 2 \times, 4 \times$ EC95; EC95 = concentration of the drug required to produce the inhibitory effect by $95 \%$ ) on the amplitude of endplate potentials and its rundown were observed. Treatment of the isolated rat phrenic nerve-diaphragm preparation with rocuronium $(2.5-20 \mu \mathrm{g} / \mathrm{ml})$ or vecuronium $(0.5-4 \mu \mathrm{g} / \mathrm{ml})$ decreased the amplitude of endplate potentials and inhibited its rundown in a concentration-dependent manner. At the concentration $(2.5 \mu \mathrm{g} / \mathrm{ml}$ for rocuronium and $0.5 \mu \mathrm{g} / \mathrm{ml}$ for vecuronium) that did not alter the endplate potential amplitude, the onset of reduced endplate potential rundown was 3 and 5 min after administration of rocuronium or vecuronium, respectively. The results suggest that rocuronium and vecuronium block the neuromuscular junction presynaptically and that rocuronium does it faster than vecuronium.
\end{abstract}

Keywords: Rocuronium, Vecuronium, Motor endplate, Neuromuscular junction, Diaphragm

\section{Background}

The isolated phrenic nerve diaphragm preparation is the most frequently used model for studying electric neurotransmission of the neuromuscular junction, which is one of the most widely studied synapses. The junction consists of three distinct parts: the presynaptic part, which is the distal nerve terminal, the synaptic cleft, and the postsynaptic part, which is a part of the muscle membrane (Fagerlund \& Eriksson 2009). Acetylcholine (ACh) is the primary neurotransmitter that is synthesized, stored and released by the nerve terminal. The transmission from nerve to muscle is completed via the release of ACh from presynapses and activation of ligand-gated, fast-acting nicotinic ACh receptors (nAChRs) on postsynapses.

Rocuronium and vecuronium, two non-depolarizing neuromuscular blockers and competitive nAChR antagonists,

\footnotetext{
*Correspondence: junlinavy@yahoo.com.cn; hzhang@hsc.wvu.edu 'Department of Anesthesiology, Navy General Hospital of PLA, Beijing 100037, China

Full list of author information is available at the end of the article
}

have been widely used in surgical procedures. While both drugs are monoquaternary aminosteroids and share a similar structure, rocuronium is much less potent, with the ED95 of $0.36 \mathrm{mg} / \mathrm{kg}$, compared to the ED95 of $0.05 \mathrm{mg} / \mathrm{kg}$ for vecuronium (Foldes et al. 1991; Xue et al. 1998). The lack of potency is considered to be an important factor in determining the onset of neuromuscular blocking (Bowman et al. 1988). Agents with less potency are more likely to achieve a rapid onset of action. Rocuronium produces the maximum effect within $2 \mathrm{~min}$, which is much more rapid than any other nondepolarizing relaxant (Bevan 1994; Nava-Ocampo et al. 2006). As for rocuronium, nearly all neuromuscular blocking molecules are bound to the postsynaptic nAChRs at the neuromuscular junction. Rocuronium also binds to the presynaptic $\mathrm{N}$-cholinergic receptor at the neuromuscular junction (Meistelman et al. 1992), leading to presynaptic inhibition (Schwarz et al. 1985). This is thought to contribute to the rapid onset of rocuronium's action (Feldman \& Hood 1994). However, electrophysiological 
evidence is still lacking for the pharmacological properties of non-depolarizing neuromuscular blockers with rapid onset of actions. In the present study, we aimed to compare the effects of rocuronium and vecuronium on initial rundown of the amplitude of endplate potentials (EPPs) in the non-uniform stretched muscle preparation of the isolated rat phrenic nerve diaphragm, in order to determine the inhibitory effect of both drugs on presynaptic transmission.

\section{Methods}

Male and female adult Wistar rats (the Animal Center of the Academy of Military Medical Sciences, Beijing, China), weighing 160-220 g, were used for the experiments. The left side of the diaphragm with the phrenic nerve was dissected from the rat following the procedures described previously (Bulbring 1997). The phrenic nerve diaphragm was kept in the Tyrode's solution with $95 \% \mathrm{O}_{2}$ and $5 \% \mathrm{CO}_{2}$. The shear diaphragm $(2 \times 2 \mathrm{~cm})$ was prepared and made into the non-uniform stretched muscle preparation. Samples were placed in the water bath, which was placed on the working platform within the network mask. The phrenic nerve was put in the hook of the stimulated electrodes; the distance between the electrodes was $1 \mathrm{~mm}$. Phrenic nerves were stimulated with $8 \mathrm{~V}$ super square wave stimulation with pulse width of $10-20 \mu$ s via the SEN-3201 stimulator connected to the SS-102 J Isolator (NihonKohden Corporation, Japan). The position of the diaphragm with very slight contraction was located and the motor endplates around the nerve fibers stretching into the diaphragm were identified using the dissecting microscope. All the animal experiments were performed following the procedures approved by the Animal Care and Use Committee of the Academy of Military Medical Sciences, Beijing, China, and the National Institute of Health Guide for the Care and Use of Laboratory Animals (NIH Publications No. 80-23, revised 1996).

Signals were outputted from the $10-\mathrm{Vm}$ connector of the amplifier to the VC-10 oscilloscope (NihonKohden Corporation, Japan) (average voltage height $=10$ ). Resting membrane potential was shown in the amplifier $\mathrm{Vm}$. The miniature EPP (MEPP) and EPP, which were amplified using the VC-10 AC (sensitivity $10 \mathrm{mV} / \mathrm{cm}$ ) and DC amplification (sensitivity $0.1 \mathrm{~V} / \mathrm{cm}$ ), respectively, were outputted and stored in the DTC-75ES tape recorder (Nihon Kohden Corporation, Japan). The signals were collected and saved in the computer from the ISC-67 module (A/D; 16-channel, 12-bit, $1 \mu \mathrm{s})$ converting board (RC Electronics Corporation, USA), with the collecting frequency $10 \sim$ $20 \mathrm{kHz}$. Signal acquisition and analysis were performed using the Computerscope-PHY system (RC Electronics Corporation, USA).

Rocuronium and vecuronium (N.V. Organon, Oss, The Netherlands) were diluted with the Tyrode's solution. The effects of rocuronium and vecuronium at the concentrations of $0.5 \times, 1 \times, 2 \times, 4 \times$ EC95 (EC95 = concentration of the drug required to produce the inhibitory effect by 95\%) on the EPP amplitude and its initial rundown (i.e., the decrease in the size of the EPP) were examined and compared with the vehicle (the Tyrode's solution) control. More specifically, each drug was tested in the following groups of concentrations: 0 (vehicle control), 2.5, 5, 10, and $20 \mu \mathrm{g} / \mathrm{ml}$ for rocuronium and 0 , $0.5,1,2$, and $4 \mu \mathrm{g} / \mathrm{ml}$ for vecuronium. All the drug concentrations were identified as the final concentrations in the $20-\mathrm{ml}$ bath. The data was recorded at three time points for each drug after administration, i.e., 1, 3, and $5 \mathrm{~min}$ after rocuronium and 3,5 , and $10 \mathrm{~min}$ after vecuronium. The concentrations and time points were determined based on our preliminary study and studies published elsewhere, which demonstrate that rocuronium is less potent and has about a half of the onset time relative to vecuronium (Xue et al. 1998; Chatrath et al. 2010). The rundown rate is the percentage of the difference between the first quantum content of EPP and the 11-55 average quantum content of EPP divided by the first quantum content of EPP in the trains of EPPs. Data collected and analyzed by the Computerscope-PHY were graphed using Origin 2.94 .

\section{Data analysis}

All values are expressed as means \pm SEM. The data were analyzed using one-way analysis of variance (ANOVA) followed by post hoc Student's $t$ tests. $P<0.05$ was considered statistically significant.

\section{Results}

Normal EPPs and trains of EPPs are shown in Figure 1A. The EPP amplitudes were not different among the concentration groups before treatment with rocuronium or vecuronium (Tables 1 and 2), suggesting similar EPP baselines before drug treatment. Rocuronium $(2.5-20 \mu \mathrm{g} / \mathrm{ml})$ decreased the amplitude of EPPs in the non-uniform stretched muscle preparation in a concentration-dependent manner. Specifically, while rocuronium at $2.5 \mu \mathrm{g} / \mathrm{ml}$ did not affect the EPP amplitude, it reduced the EPP amplitude at the concentration of $5 \mu \mathrm{g} / \mathrm{ml}$ at 3 and $5 \mathrm{~min}$ after drug administration $(P<0.05$ and $P<0.01$, respectively); at higher concentrations of 10 and $20 \mu \mathrm{g} / \mathrm{ml}$, rocuronium decreased the EPP amplitude at all the three time points (i.e., 1,3 , and 5 min after drug administration; $P<0.05$ or $P<0.01$; Table 1 ).

Similar to rocuronium, vecuronium at $0.5-4 \mu \mathrm{g} / \mathrm{ml}$ also decreased the EPP amplitude in the non-uniform stretched muscle preparation in a concentration-dependent manner. More specifically, while vecuronium at $0.5 \mu \mathrm{g} / \mathrm{ml}$ did not affect the EPP amplitude compared to the control, it reduced the EPP amplitude at $1 \mu \mathrm{g} / \mathrm{ml}$ at 5 and $10 \mathrm{~min}$ after drug administration $(P<0.05$ and 


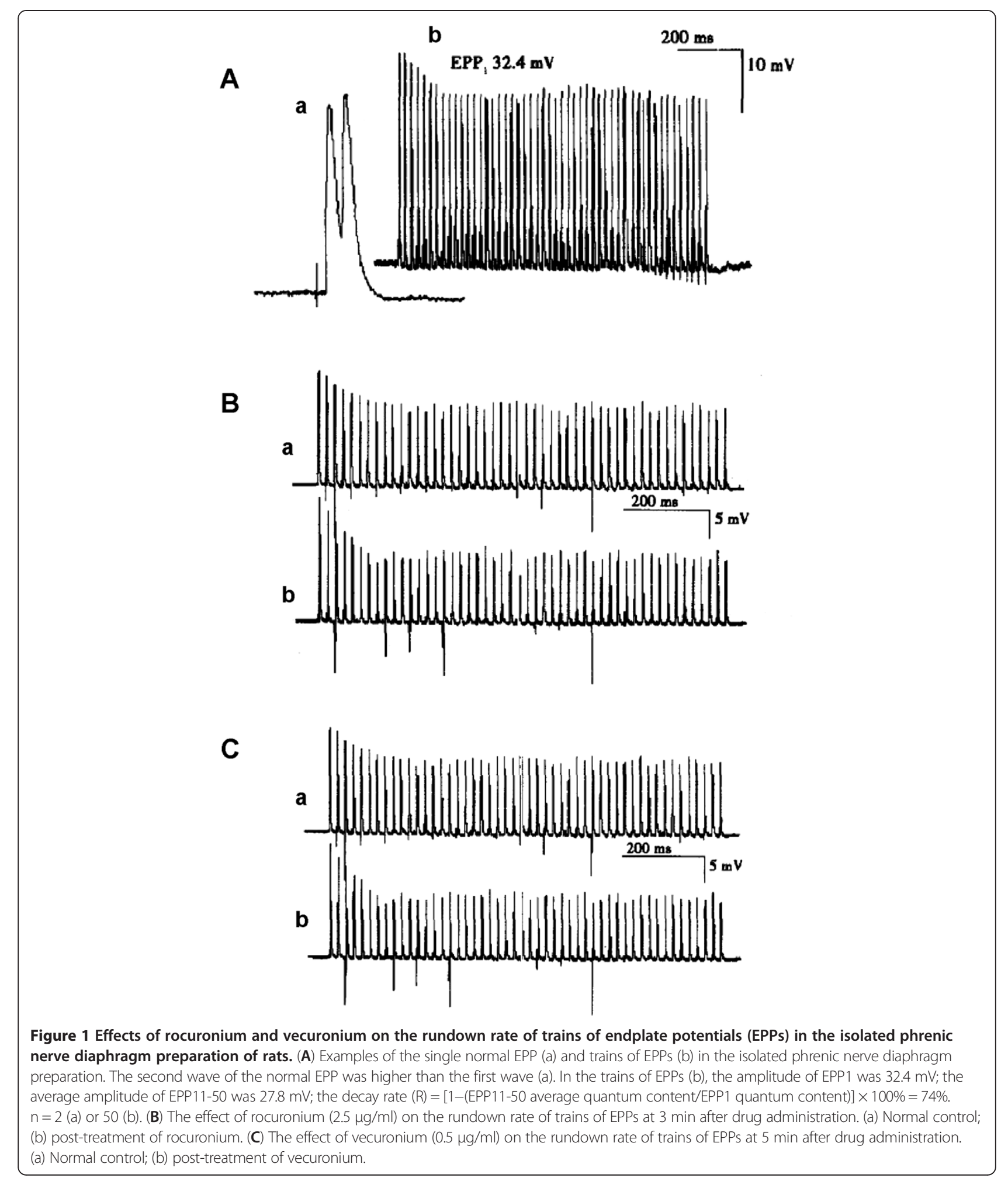

$P<0.01$, respectively; Table 2 ). At the higher concentrations of 2 and $4 \mu \mathrm{g} / \mathrm{ml}$, vecuronium decreased the EPP amplitude at all the three time points (i.e., 3, 5, and $10 \mathrm{~min}$ after drug administration $(P<0.05$ or $P<0.01)$.
To compare the onset and potency of the actions, we examined the rundown rates of EPP amplitudes at 3 and $5 \mathrm{~min}$ after treatment with rocuronium or vecuronium, each at the concentration that did not alter the EPP amplitude (i.e., $2.5 \mu \mathrm{g} / \mathrm{ml}$ for rocuronium and $0.5 \mu \mathrm{g} / \mathrm{ml}$ for 
Table 1 Effects of rocuronium on the amplitude of endplate potentials (EPPs) in the isolated rat phrenic nerve diaphragm preparation at different time points after treatment

\begin{tabular}{|c|c|c|c|c|}
\hline \multirow{2}{*}{$\begin{array}{l}\text { Rocuronium } \\
\qquad(\mu \mathrm{g} / \mathrm{ml})\end{array}$} & \multirow{2}{*}{$\begin{array}{c}\mathrm{EPP}(\mathrm{mV}) \\
\text { before } \\
\text { treatment }\end{array}$} & \multicolumn{3}{|c|}{ EPP $(\mathrm{mV})$ at different times after treatment } \\
\hline & & $1 \mathrm{~min}$ & $3 \mathrm{~min}$ & $5 \mathrm{~min}$ \\
\hline Control & $32.4 \pm 3.3$ & $32.2 \pm 3.4$ & $32.2 \pm 3.3$ & $31.4 \pm 3.5$ \\
\hline 2.5 & $32.6 \pm 3.6$ & $32.3 \pm 3.4$ & $32.1 \pm 3.5$ & $31.2 \pm 3.3$ \\
\hline 5.0 & $33.5 \pm 3.4$ & $32.4 \pm 3.3$ & $22.4 \pm 2.9^{* \#}$ & $14.6 \pm 2.1^{* * \# \#}$ \\
\hline 10.0 & $34.8 \pm 4.3$ & $27.2 \pm 2.5^{* *}$ & $16.4 \pm 1.3^{* * \# \#}$ & $12.4 \pm 1.3^{* * \# \#}$ \\
\hline 20.0 & $33.2 \pm 3.1$ & $22.4 \pm 2.3^{* \#}$ & $12.4 \pm 2.3^{* \#}$ & $9.4 \pm 1.1^{* * \# \#}$ \\
\hline
\end{tabular}

vecuronium). Treatment with either of the drugs at the low concentration decreased initial rundown rates of EPP trains. Rocuronium had slightly greater efficacy at $2.5 \mu \mathrm{g} / \mathrm{ml} 3 \mathrm{~min}$ after administration relative to vecuronium at $0.5 \mu \mathrm{g} / \mathrm{ml}$ 5 min after administration (Figure $1 \mathrm{~B}, \mathrm{C}$ ). In addition, compared to vecuronium, rocuronium generated trains of EPP rundown earlier, while the potency is smaller $(2.5 \mu \mathrm{g} / \mathrm{ml} \mathrm{vs}$. $0.5 \mu \mathrm{g} / \mathrm{ml}$ required respectively to generate the maximum effect; Table 3).

\section{Discussion}

The neuromuscular junction is a typical class of peripheral cholinergic synapses. Under normal circumstances, nerve stimulation produces presynaptic release of a large number of ACh, leading to a postsynaptic endplate potential and a subsequent mechanical contraction via muscle action potentials. In physiological conditions, a bunch of nerve impulses (about $50 \mathrm{~Hz}$ ) stimulates release of a large amount of ACh from presynaptic nerve endings; as the neurotransmitter, ACh produces trains of postsynaptic membrane potentials and endplate action potentials, leading to tonic muscle contraction. ACh in the synaptic cleft (gap) is rapidly hydrolyzed by $\mathrm{AChE}$, causing a rapid decrease in the ACh level to that before ACh release and subsequently terminates the role of ACh timely and effectively. This rapidly repolarizes the postsynaptic membrane potential for responding to the next release of ACh (Martin 2005). The attenuation of $50-\mathrm{Hz}$ or $100-\mathrm{Hz}$ tonic stimulation is resulted from blockade of presynaptic receptors. There are two types of vesicles for presynaptic release of $\mathrm{ACh}$ : immediate release vesicles and storage vesicles. Under the tonic stimulation of $50 \mathrm{~Hz}$ or $100 \mathrm{~Hz}$, $\mathrm{ACh}$ immediate-release vesicles are empty while $\mathrm{ACh}$ is continuously transported from storage vesicles, leading to decreases in ACh levels, EPP amplitudes, and rundown rates of EPP trains. These in turn result in feedback regulation of ACh, which maintains normal physiological function by preventing EPP rates from further decreases (Bowman 1990). In the present study, we examined the presynaptic effects of rocuronium and vecuronium based on the initial attenuation of trains of EPPs caused by 50 $\mathrm{Hz}$ tonic stimulation.

In the neuromuscular junction, $\mathrm{ACh}$ in the synaptic cleft can play a positive or negative role in the feedback regulation of $\mathrm{ACh}$ release from nerve terminals via the action on presynaptic nAChRs (Fagerlund \& Eriksson 2009; Wessler 1989). More specifically, ACh at low or physiological concentrations plays a positive feedback role in ACh release, leading to increased immediate-release vesicles transferred from storage vesicles in the nerve endings. The positive feedback mechanism allows nerve-muscle tissues to adapt to high-frequency stimulation $(>1 \mathrm{~Hz}$ ) (Bowman 1980). In contrast, ACh at high concentrations plays a negative feedback role in ACh release, leading to depolarization of the nerve terminals. These two feedback mechanisms may affect the onset of actions of non-depolarizing muscle relaxants to a certain extent. The non-uniform stretched muscle preparation from the isolated rat phrenic nerve

Table 2 Effects of vecuronium on the amplitude of endplate potentials (EPPs) in the isolated rat phrenic nerve diaphragm preparation at different time points after treatment

\begin{tabular}{|c|c|c|c|c|}
\hline \multirow{2}{*}{$\begin{array}{l}\text { Vecuronium } \\
(\mu \mathrm{g} / \mathrm{ml})\end{array}$} & \multirow{2}{*}{$\begin{array}{l}\text { EPP }(\mathrm{mV}) \text { before } \\
\text { administration }\end{array}$} & \multicolumn{3}{|c|}{ EPP $(\mathrm{mV})$ at different times after treatment } \\
\hline & & $3 \mathrm{~min}$ & $5 \mathrm{~min}$ & $10 \mathrm{~min}$ \\
\hline Control & $32.4 \pm 3.3$ & $32.2 \pm 3.3$ & $31.4 \pm 3.2$ & $31.2 \pm 2.9$ \\
\hline 0.5 & $32.3 \pm 3.4$ & $31.7 \pm 2.9$ & $30.6 \pm 3.3$ & $29.7 \pm 2.2$ \\
\hline 1.0 & $31.5 \pm 3.2$ & $27.4 \pm 2.7$ & $22.4 \pm 2.8^{*}$ & $16.4 \pm 2.1^{* * \# \#}$ \\
\hline 2.0 & $33.1 \pm 3.4$ & $22.4 \pm 3.3^{* \#}$ & $14.4 \pm 1.4^{* * \# \#}$ & $12.4 \pm 1.3^{* * \# \#}$ \\
\hline 4.0 & $32.7 \pm 3.1$ & $18.4 \pm 3.3^{* * \# \#}$ & $12.4 \pm 1.5^{* * \# \#}$ & $8.4 \pm 1.3^{* * \# \#}$ \\
\hline
\end{tabular}


Table 3 Changes in string initial rundown rates of endplate potentials (EPPs) before and after treatment of the isolated rat phrenic nerve diaphragm preparation with rocuronium or vecuronium

\begin{tabular}{|c|c|c|c|c|c|c|c|c|c|}
\hline \multirow[t]{2}{*}{ Drug $(\mu \mathrm{g} / \mathrm{ml})$} & \multicolumn{3}{|c|}{ Before treatment } & \multicolumn{3}{|c|}{3 min after treatment } & \multicolumn{3}{|c|}{$5 \mathrm{~min}$ after treatment } \\
\hline & M1 & MX & $\mathrm{R}(\%)$ & M1 & MX & R (\%) & M1 & $\mathrm{MX}$ & R (\%) \\
\hline Rocuronium 2.5 & $46 \pm 11$ & $34 \pm 10$ & 26 & $46 \pm 10$ & $28 \pm 10$ & $40^{*}$ & $45 \pm 12$ & $26 \pm 10^{*}$ & $42^{*}$ \\
\hline Vecuronium 0.5 & $46 \pm 11$ & $33 \pm 11$ & 28 & $46 \pm 11$ & $31 \pm 10$ & 33 & $45 \pm 12$ & $29 \pm 11^{*}$ & $37^{*}$ \\
\hline
\end{tabular}

${ }^{*} P<0.05$, compared with the corresponding group without drug treatment; $n=5$. M1, the first quantum content of EPP; $M X$, the 11 to 55 average quantum content of EPP; $R$, the rundown rate. $M=V c / q ; V c$ is the corrected amplitude of EPP and $q$ is the quantum size of the MEPP. Data shown are means $\pm S E M$.

diaphragm is used to record relatively high rates of EPPs and miniature EPPs (Zou \& Liu 1988). Using this approach, we recorded an average of $30 \mathrm{mV}$ of EPP.

There are two types of rundown: intratrain rundown (reduction in the EPP size from one train to the next), which is frequency-dependent, and intertrain rundown (reduction in the EPP size within a train), which is relatively independent of stimulation frequency during intermittent stimulation (Moyer \& van Lunteren 1999). The initial rundown (intratrain rundown) of the EPP amplitude usually decreases quickly within a train but recovers almost completely from train to train during intermittent stimulation. In the present study, administration of rocuronium or vecuronium decreased both intratrain rundown and intertrain rundown of EPPs.

While most neuromuscular blocking agents act on postsynaptic nicotinic receptors at the neuromuscular junction, several lines of evidence also suggest a presynaptic role of rocuronium and vecuronium. The impact of rocuronium on the EPP initial rundown is related to the frequency of stimulation: the higher stimulus frequency, the more initial rundown. This feature indicates that rocuronium may have a potent presynaptic effect (Feldman \& Khaw 1995). This is supported by the presynaptic effect of vecuronium (Schwarz et al. 1985). In addition, using the isolated human forearm, England and co-workers have demonstrated that rocuronium produces non-depolarizing blockade in a manner different from other non-depolarizing muscle relaxants in terms of onset and/or recovery (England et al. 1996), suggesting that rocuronium exerts a presynaptic effect. Further, more directly, rocuronium binds to the presynaptic N-cholinergic receptors at the neuromuscular junction, leading to presynaptic inhibition (Meistelman et al. 1992; Feldman \& Hood 1994).

Both rocuronium and vecuronium enhances ACh release from presynapses. Compared to vecuronium, rocuronium acts on EPP amplitudes with slightly greater efficacy and faster onset, but smaller potency. It is speculated that rocuronium has faster and greater presynaptic inhibition (Li \& Zhang 2004). The inhibitory effects of the drugs on the initial rundown of EPP amplitudes indicate that presynaptic inhibition by rocuronium may be related to the direct effect on presynaptic nAChRs, leading to reduced transport of neurotransmitters in presynapses.
Of note, sensitivity to rocuronium and/or vecuronium may vary in certain medical conditions interfering with neurotransmission at the neuromuscular junction. For instance, patients with myasthenia gravis, an autoimmune disorder involving the destruction of AChRs at the postsynaptic membrane at the neuromuscular junction, are hypersensitive to nondepolarizing neuromuscular blocking drugs such as vecuronium, which can make the characteristic symptoms such as fatigue worse (Itoh et al. 2002). Similarly, patients with neuromyotonia, a disorder of hyperexcitability of the peripheral nerve and characterized by both myokymic and neuromyotonic discharges, also exhibit increased sensitivity to the neuromuscular effects of rocuronium (Ginsburg et al. 2009). Thus, lower doses of rocuronium/vecuronium should be administered for anesthesia in patients with these disorders.

In conclusions, both rocuronium and vecuronium enhance initial rundown of EPP amplitudes in the isolated phrenic nerve diaphragm preparation of rats, suggesting that both drugs produce significant presynaptic inhibition. Compared to vecuronium, rocuronium is slightly greater in efficacy and faster in onset, but smaller in potency of blocking the neuromuscular junction.

\section{Competing interests}

The authors declare that they have no competing interests.

\section{Authors' contributions}

$J$ designed and carried out the electrophysiological experiments and drafted the manuscript; YQL performed the isolated phrenic nerve diaphragm preparation and recordings; HTZ designed the experiments, drafted and revised the manuscript. All authors read and approved the final manuscript.

\section{Author details}

${ }^{1}$ Department of Anesthesiology, Navy General Hospital of PLA, Beijing 100037, China. ${ }^{2}$ Departments of Behavioral Medicine \& Psychiatry and Physiology \& Pharmacology, West Virginia University Health Sciences Center, Morgantown, WV 26506, USA.

Received: 23 December 2012 Accepted: 4 April 2013 Published: 11 April 2013

\section{References}

Bevan DR (1994) Newer neuromuscular blocking agents. Pharmacol Toxicol 74:3-9

Bowman WC (1980) Prejunctional and postjunctional cholinoceptors at the neuromuscular junction. Anesth Analg 59:935-943

Bowman WC (ed) (1990) Pharmacology of neuromuscular function, 2nd edn. Wright, London, p 90

Bowman WC, Rodger IW, Houston J, Marshall RJ, McIndewar I (1988) Structure: action relationships among some desacetoxy analogues of pancuronium and vecuronium in the anesthetized cat. Anesthesiology 69:57-62 
Bulbring E (1997) Observations on the isolated phrenic nerve diaphragm preparation of the rat. 1946. Br J Pharmacol 120:3-26

Chatrath V, Singh I, Chatrath R, Arora N (2010) Comparison of intubating conditions of rocuronium bromide and vecuronium bromide with succinylcholine using "timing principle". J Anaesthesiol Clin Pharmacol 26:493-497

England AJ, Panikkar K, Redai I, Haxby E, Gopinath S, Feldman SA (1996) Is rocuronium an exception to the relation between onset and offset? A comparison with pipecuronium. Eur J Anaesthesiol 13:385-388

Fagerlund MJ, Eriksson LI (2009) Current concepts in neuromuscular transmission. Br J Anaesth 103:108-114

Feldman S, Hood J (1994) Depolarizing neuromuscular block-a presynaptic mechanism? Acta Anaesthesiol Scand 38:535-541

Feldman SA, Khaw K (1995) The effect of dose and the rate of stimulation on the action of rocuronium. Eur J Anaesthesiol Suppl 11:15-17

Foldes FF, Nagashima H, Nguyen HD, Schiller WS, Mason MM, Ohta Y (1991) The neuromuscular effects of ORG9426 in patients receiving balanced anesthesia. Anesthesiology 75:191-196

Ginsburg G, Forde R, Martyn JA, Eikermann M (2009) Increased sensitivity to a nondepolarizing muscle relaxant in a patient with acquired neuromyotonia. Muscle Nerve 40:139-142

Itoh H, Shibata K, Nitta S (2002) Sensitivity to vecuronium in seropositive and seronegative patients with myasthenia gravis. Anesth Analg 95:109-113

$\mathrm{Li}$ J, Zhang H (2004) Effects of rocuronium on miniature endplate potentials and endplate potentials in the isolated phrenic nerve diaphragm preparation of rats. Med J Chin PLA 29:64-65

Martin AR (2005) Quantal nature of synaptic transmission. Physiol Rev 46:51-66

Meistelman C, Plaud B, Donati F (1992) Rocuronium (ORG 9426) neuromuscular blockade at the adductor muscles of the larynx and adductor pollicis in humans. Can J Anaesth 39:665-669

Moyer M, van Lunteren E (1999) Effect of phasic activation on endplate potential in rat diaphragm. J Neurophysiol 82:3030-3040

Nava-Ocampo AA, Velázquez-Armenta Y, Moyao-García D, Salmerón J (2006) Meta-analysis of the differences in the time to onset of action between rocuronium and vecuronium. Clin Exp Pharmacol Physiol 33:125-130

Schwarz S, llias W, Lackner F, Mayrhofer O, Foldes FF (1985) Rapid tracheal intubation with vecuronium: the priming principle. Anesthesiology 62:388-391

Wessler I (1989) Control of transmitter release from the motor nerve by presynaptic nicotinic and muscarinic autoreceptors. Trends Pharmacol Sci 10:110-114

Xue FS, Liao X, Liu JH, Tong SY, Zhang YM, Zhang RJ, An G, Luo LK (1998) A comparative study of the dose-response and time course of action of rocuronium and vecuronium in anesthetized adult patients. J Clin Anesth 10:410-415

Zou F, Liu C-G (1988) The presynaptic and postsynaptic role of soman in uneven stretch muscles in isolated rat diaphragm specimens. Chin Pharmacol Toxicol 2:113-121

doi:10.1186/2193-1801-2-155

Cite this article as: Li et al:: Effects of rocuronium and vecuronium on initial rundown of endplate potentials in the isolated phrenic nerve diaphragm preparation of rats. SpringerPlus 2013 2:155.

\section{Submit your manuscript to a SpringerOpen ${ }^{\circ}$ journal and benefit from:}

- Convenient online submission

- Rigorous peer review

- Immediate publication on acceptance

- Open access: articles freely available online

- High visibility within the field

- Retaining the copyright to your article

Submit your next manuscript at $\gg$ springeropen.com 